\title{
Unil
}

UNIL | Université de Lausanne

Unicentre

$\mathrm{CH}-1015$ Lausanne

http://serval.unil.ch

Year : 2014

\section{COMPARISONS OF PREOPERATIVE THREEDIMENSIONAL PLANNING AND SURGICAL RECONSTRUCTION IN PRIMARY CEMENTLESS TOTAL HIP ARTHROPLASTY}

\author{
HASSANI Hassen
}

\begin{abstract}
HASSANI Hassen, 2014, COMPARISONS OF PREOPERATIVE THREEDIMENSIONAL PLANNING AND SURGICAL RECONSTRUCTION IN PRIMARY CEMENTLESS TOTAL HIP ARTHROPLASTY
\end{abstract}

Originally published at: Thesis, University of Lausanne

Posted at the University of Lausanne Open Archive http://serval.unil.ch

Document URN : urn:nbn: ch:serval-BIB_CEF44163BC896

\section{Droits d'auteur}

L'Université de Lausanne attire expressément l'attention des utilisateurs sur le fait que tous les documents publiés dans l'Archive SERVAL sont protégés par le droit d'auteur, conformément à la loi fédérale sur le droit d'auteur et les droits voisins (LDA). A ce titre, il est indispensable d'obtenir le consentement préalable de l'auteur et/ou de l'éditeur avant toute utilisation d'une oeuvre ou d'une partie d'une oeuvre ne relevant pas d'une utilisation à des fins personnelles au sens de la LDA (art. 19, al. 1 lettre a). A défaut, tout contrevenant s'expose aux sanctions prévues par cette loi. Nous déclinons toute responsabilité en la matière.

\section{Copyright}

The University of Lausanne expressly draws the attention of users to the fact that all documents published in the SERVAL Archive are protected by copyright in accordance with federal law on copyright and similar rights (LDA). Accordingly it is indispensable to obtain prior consent from the author and/or publisher before any use of a work or part of a work for purposes other than personal use within the meaning of LDA (art. 19, para. 1 letter a). Failure to do so will expose offenders to the sanctions laid down by this law. We accept no liability in this respect. 
UNIVERSITE DE LAUSANNE - FACULTE DE BIOLOGIE ET DE MEDECINE

DAL / Service d'orthopédie et traumatologie CHUV

COMPARISONS OF PREOPERATIVE THREEDIMENSIONAL PLANNING AND

SURGICAL RECONSTRUCTION IN PRIMARY CEMENTLESS TOTAL HIP ARTHROPLASTY

\begin{abstract}
THESE
préparée sous la direction du Professeur Alain Farron

(avec la co-direction du PD Dr Hannes A Rüdiger)

et présentée à la Faculté de biologie et de médecine de l'Université de Lausanne pour l'obtention du grade de
\end{abstract}

DOCTEUR EN MEDECINE

par

Hassen HASSANI

Médecin diplômé de la République d'Algérie

Originaire de Vernier (Genève)

Lausanne

2014 


\section{$u_{n}$}

UNIL | Université de Lausanne

Faculté de biologie et de médecine

Ecole Doctorale

Doctorat en médecine

\section{Imprimatur}

Vu le rapport présenté par le jury d'examen, composé de

Directeur de thèse Monsieurle Professeur Alain Farron

Co-Directeur de thèse

Expert Monsieur le Professeur Jean-Philippe Thiran

Directrice de l'Ecole Madame le Professeur Stephanie Clarke

doctorale

la Commission MD de l'Ecole doctorale autorise l'impression de la thèse de

Monsieur Hassen Hassani

intitulée

Comparisons of preoperative threedimensional planning and surgical reconstruction in primary cementless total hip arthroplasty

Lausanne, le 20 mai 2014

pour Le Doyen

de la Faculté de Biologie et de Médecine

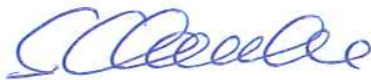

Madame le Professeur Stephanie Clarke

Directrice de l'Ecole doctorale 


\title{
Comparisons of Preoperative Three-Dimensional Planning and Surgical Reconstruction in Primary Cementless Total Hip Arthroplasty
}

\author{
Hassen Hassani, MD ${ }^{\text {a }}$, Stéphane Cherix, MD ${ }^{\text {a }}$, Eugene T. Ek, MBBS, PhD, FRACS ${ }^{\text {}}$, Hannes A. Rüdiger, MD ${ }^{\text {a }}$ \\ a Department of Orthopaedics Hôpital Orthopédique-Centre Hospitalier Universitaire Vaudois, University of Lausanne, Switzerland \\ ${ }^{\mathrm{b}}$ Melbourne Orthopaedic Group and Department of Orthopaedic Surgery, Monash University, Dandenong Hospital, Melbourne, Australia
}

\section{A R T I C L E I N F O}

Article history:

Received 5 November 2013

Accepted 30 December 2013

\section{Keywords:}

total hip arthroplasty

preoperative planning

hip reconstruction

anatomical reconstruction

3D templating

\begin{abstract}
A B S T R A C T
Reconstruction of important parameters such as femoral offset and torsion is inaccurate, when templating is based on plain X-rays. We evaluate intraoperative reproducibility of pre-operative CT-based 3D-templating in a consecutive series of 50 patients undergoing primary cementless THA through an anterior approach. Pre-operative planning was compared to a postoperative CT scan by image fusion. The implant size was correctly predicted in $100 \%$ of the stems, $94 \%$ of the cups and $88 \%$ of the heads (length). The difference between the planned and the postoperative leg length was $0.3+2.3 \mathrm{~mm}$. Values for overall offset, femoral anteversion, cup inclination and anteversion were $1.4 \mathrm{~mm} \pm 3.1,0.6^{\circ} \pm 3.3^{\circ},-0.4^{\circ} \pm 5^{\circ}$ and $6.9^{\circ} \pm 11.4^{\circ}$, respectively. This planning allows accurate implant size prediction. Stem position and cup inclination are accurately reproducible.
\end{abstract}

(c) 2014 Elsevier Inc. All rights reserved.
The importance of preoperative planning for implant selection, positioning and orientation of components and adjustment of leg length has been well documented in the literature [1-5]. Classically, templating is performed using a plain anteroposterior (AP) x-ray of the pelvis [1]. However, due to individual patient anatomy and variations in magnification and projection, important radiographic parameters are not always reliable on plain x-rays. For example, due to the variations in femoral antetorsion between individuals, femoral offset may be underestimated in most cases [5]. In addition, accurate definition of the intramedullary anatomy is often insufficient on plain radiographs, but this plays an important role in templating for proper implant selection. As such, three-dimensional (3D) planning based on CT scans has the potential to overcome these short-comings. This technique, introduced by Sariali et al [6], based on HIP-PLAN software (Symbios, Yverdon-les-Bains/Switzerland) allows pre-operative accurate quantification of anatomy and facilitates virtual implant positioning.

The aim of this present study is to assess the intra-operative reproducibility of the pre-operative three-dimensional planning in a consecutive series of patients undergoing primary total hip arthroplasty through a direct anterior approach.

The Conflict of Interest statement associated with this article can be found at http:// dx.doi.org/10.1016/j.arth.2013.12.033.

Reprint requests: Hannes A. Rüdiger, MD, Hôpital Orthopédique/CHUV, Av. PierreDecker 4, 1011 Lausanne, Switzerland.

\section{Patients and Methods}

A prospective series of 50 consecutive patients undergoing primary cementless total hip arthroplasty was evaluated. All patients were operated by a single surgeon (HAR) through a direct anterior approach (Hueter [7]) in supine position on a traction table. Pre-operative CTbased plans were compared with a post-operative CT-scan. This study was approved by our institutional ethical committee and each patient gave written consent for participation.

\section{Three-Dimensional Planning}

All cases were preoperatively templated by the senior author (HAR). A CT-scan of the pelvis was performed according to a protocol, which comprised of a scout view of the entire leg and pelvis, with cuts at the level of the distal femur and the ankle [8]. Three-dimensional planning was performed using the templating software HIP-PLAN (version 0.91.70, Symbios SA, Yverdon-Les-Bains, Switzerland) as described previously [6,9]. Briefly, leg length is assessed on the scout view. The anterior pelvic plane (defined by the anterior superior iliac spines and pubic tubercles) as well as the axis of the proximal third of the femur served as reference points for the acetabular component and the stem respectively. Based on this, the position and orientation of the native acetabulum with its center of rotation are determined. The center of the femoral head and the bicondylar line at the level of the posterior femoral condyles serve to quantify antetorsion and true offset. 


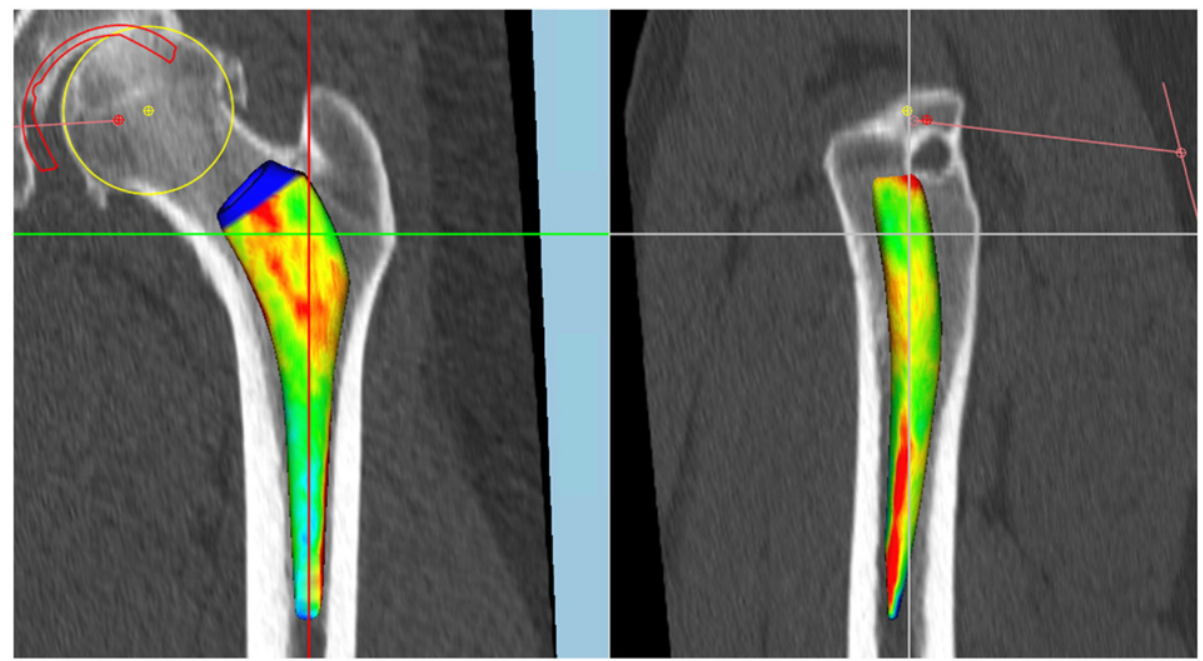

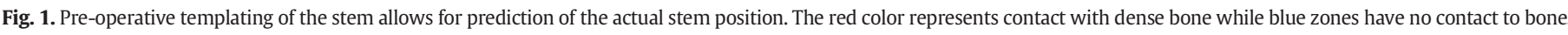

The cup size is determined according to the anteroposterior diameter of the aceabulum. The inclination is planned at $45^{\circ}$ with an anatomical anteversion. The prosthetic center of rotation is medialized, bringing the cup in contact with the medial acetabular wall.

The stem size is selected to maximize fit and fill of the femoral metaphysis. To facilitate prediction of stem size and position, HIPPLAN calculates the density of bone at the surface of the stem and illustrates that in a false color mode (Fig. 1). In a second step, extramedullary reconstruction is planned by selecting the appropriate neck (the range of the SPS prosthesis includes various necks [straight (neck-shaft angle $134^{\circ}$ ), varus/valgus, anteversion and retroversion, short and long and combinations thereof, as well as two non-modular stems with the same intramedullary shape but a fixed neck].

HIP-PLAN calculates then the distance between the top of the lesser trochanter and the tip of the cone and the level of the neck osteotomy, which both serve as important references during surgery. In addition, a virtual of the neck osteotomy plane with the position of the stem is generated, which also serves as an important intraoperative marker.
Comparison of Pre-Operative Planning With Post-Operative CT-Scan

A postoperative CT-scan was obtained during the hospitalization within the first 5 days after the operation. Using HIP-PLAN, the numerical templates are superimposed on the cup and stem (Fig. 2). The pre-operative planning CT-scan is then aligned with postoperative CT-scan, as described previously [6]. This is performed separately for the pelvis and femur due to variations in the patient position in the two scans. Finally, HIP-PLAN quantifies the difference of the position of the pre-operative and post-operative templates of the implants in the three dimensions.

\section{Surgical Procedure}

The patients were positioned on a traction table (SchaererMedical, Münsingen, Switzerland) with minimal traction on both legs to allow for a straight position of the pelvis. Total hip arthroplasty was performed in all cases through a direct anterior approach as described by Hueter [7]. Briefly, to protect the lateral cutaneous
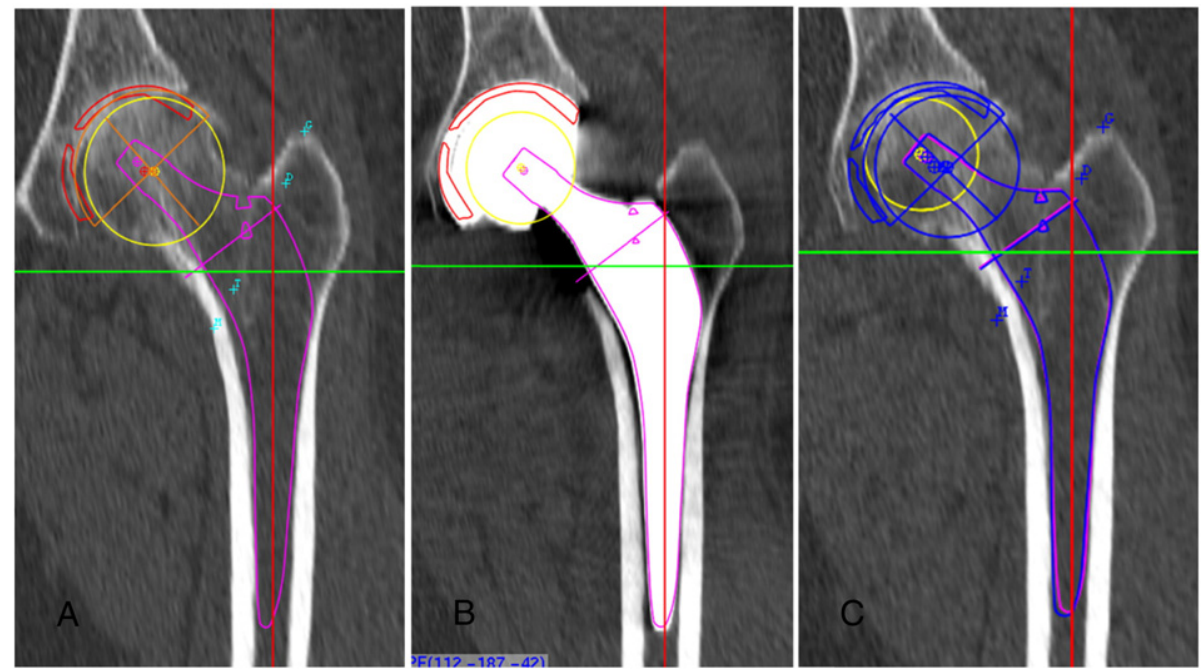

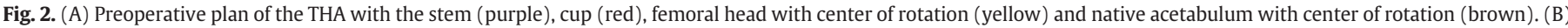

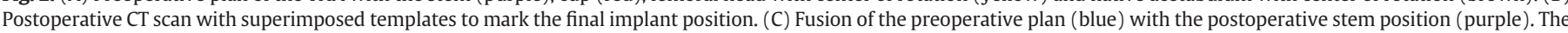
fusion has to be done separately for the femur and the pelvis to account for differences of the position of the patient during the two CT scans. 
femoral nerve, the approach passes through the tendon sheath of the tensor fasciae latae, which is retracted laterally. The tendon sheath of the rectus femoris is opened and the muscle belly is retracted medially, exposing the innominate fascia. The ascending branches of the lateral circumflex artery are identified just underneath this and ligated. The joint capsule is exposed by detaching the fibers of the iliocapsularis muscle from the capsule. The capsulotomy is performed in a V-shape fashion, parallel to the anterior acetabular wall, with the apex medial to the calcar. Laterally, the capsule is detached from the anterior intertrochanteric line, which serves as a landmark for the following osteotomy of the femoral neck. The femoral head is removed and the acetabulum is prepared for reaming.

After cup implantation, the femoral osteotomy is exposed with the in leg hyper-extension and external rotation. In order to avoid a fracture of the greater trochanter, a capsular release is necessary in most of cases. The femoral medullary canal was prepared with standard broaches, and curettes according to the 3D planning. Care was taken to not unnecessarily remove cancellous bone but rather to compress it with the broaches. The true distance between the lesser trochanter and the tip of the cone, and the calculated top-view on the osteotomy with the prosthesis in situ, as calculated by HIP-PLAN, both served as critical intraoperative guidance. In cases, in which a modular prosthesis was used, the definitive stem and the predetermined neck were pre-assembled on the back table to avoid any impurities on the stem-neck junction. After stem implantation, the joint was reduced with the planned trial head. The length of the head was intraoperatively adjusted according to the soft tissue tension.

All cases were performed without the use of intra-operative imaging. No trial implants were used except for trial heads.

\section{Results}

The series included 50 patients ( 20 males) with 50 total hip arthroplasties. The mean age was $64 \pm 13$ years (range 36-82). In all patients a stem of the SPS family (Symbios, Yverdon/Switzerland) was implanted including 36 stems with a modular neck. The stem size and the neck type were correctly predicted in all cases. The head length was correctly predicted in $44 / 50$ cases (88\%), in three cases a longer head $(+4 \mathrm{~mm})$ and in three cases a smaller head $(-4 \mathrm{~mm})$ were chosen. The mean cup size was $51 \pm 4 \mathrm{~mm}$ (44-60 mm), and was correctly predicted in $47 / 50$ cases (94\%). In three cases a larger cup was chosen $(+2 \mathrm{~mm}$ each).

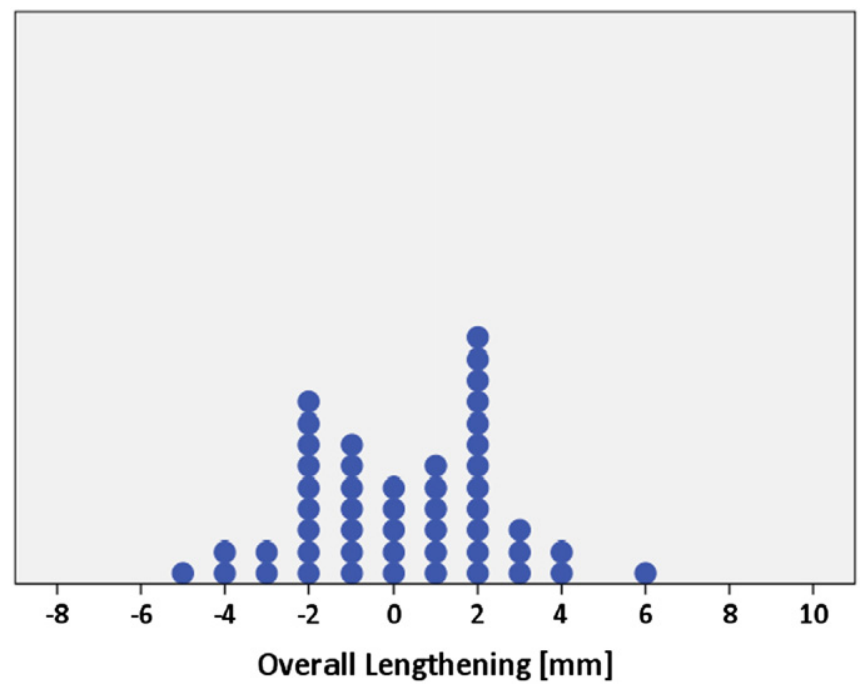

Fig. 3. The difference between the planned and the final overall leg length. Each dot represents a patient.

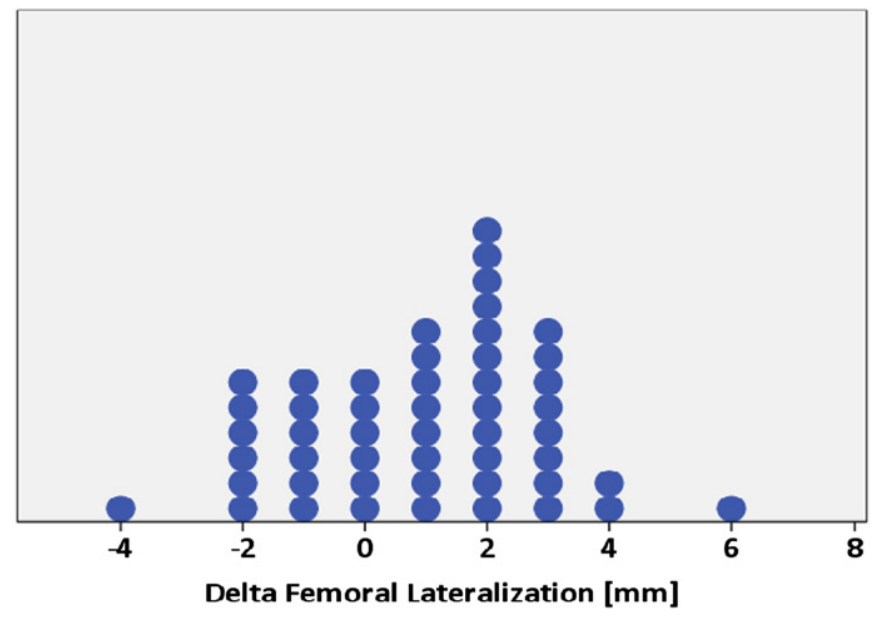

Fig. 4. Difference between the planned and the final femoral offset. Each dot represents a patient.

An average leg lengthening of the leg of $3.5 \mathrm{~mm} \pm 2.5$ (range, -1 to 14) was planned. After total hip implantation a lengthening of $3.8 \mathrm{~mm} \pm 2.9$ (range, -3 to 12 ) was achieved, resulting in a difference between the planned and the achieved leg length of $0.3 \mathrm{~mm} \pm 2.3$ (range, -5 to 6 ) (Fig. 3). The difference between the planned and the achieved overall femoral lateralization (i.e. the sum of cup lateralization and changes of femoral offset) was $1.4 \mathrm{~mm} \pm 3.1$ (range, -5 to 7 ).

The distance between the planned and the final position of the femoral center of rotation was $3.7 \pm 1.3 \mathrm{~mm}$ (range, 1 to 8 ). This value is composed of a difference in the cranio-caudal direction of $-0.2 \mathrm{~mm} \pm$ 1.9 (range, -5 to 3), in medio-lateral direction (i.e. femoral offset) of 1 $\mathrm{mm} \pm 2$ (range, -4 to 6 ) (Fig. 4) and in antero-posterior direction of 0.4 $\mathrm{mm} \pm 2.6$ (range, -6 to 6 ). The femoral antetorsion differed by $0.6^{\circ} \pm$ $3.3^{\circ}$ (range, -7 to 8 ) (Fig. 5 ).

In comparison with the planned position, the acetabular center of rotation was displaced by $3.5 \pm 1.5$ (range, 1 to 8 ). The acetabular center of rotation differed from the planned position in cranio-caudal direction by $0.4 \mathrm{~mm} \pm 1.7$ (range, -3 to 4 ), in medio-lateral direction by $0.4 \mathrm{~mm} \pm 2.6$ (range, -5 to 7 ) and in antero-posterior direction by $1.2 \mathrm{~mm} \pm 1.7$ (range, -6 to 2 ).

In every case, an acetabular inclincation of $45^{\circ}$ was planned. Final cup inclination was $44.5^{\circ} \pm 5.1^{\circ}$ (range, $36^{\circ}$ to $55^{\circ}$ ). Cup anteversion was planned according to the patients' individual anatomy. The final cup version differed from the planned version by $6.9^{\circ} \pm 11.4^{\circ}$.

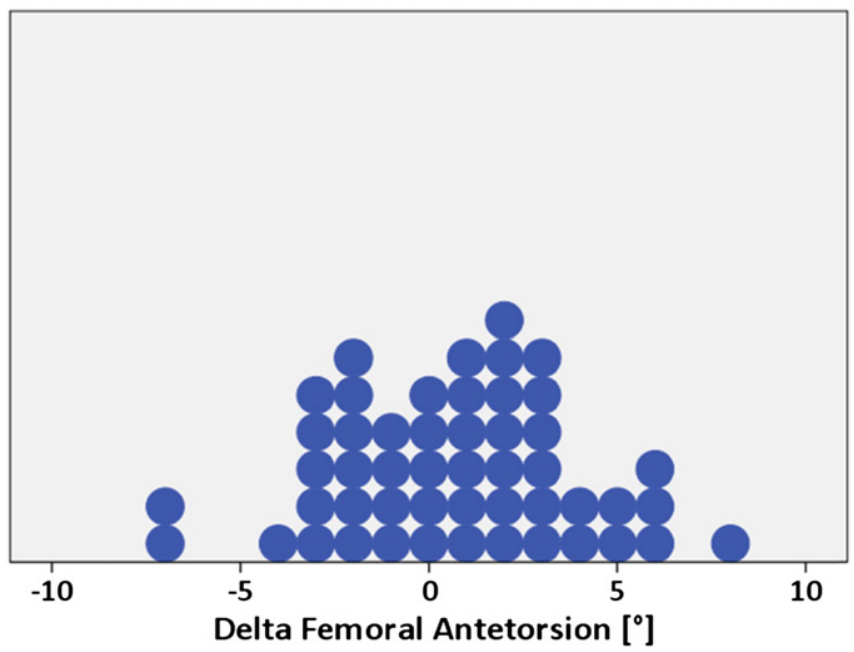

Fig. 5. Difference between the planned and the final femoral antetorsion. Each dot represents a patient. 


\section{Discussion}

Proper implant positioning in total hip arthroplasty is critical to achieve a good outcome in terms of gait pattern [10], dislocation rate $[11,12]$ and leg-length [13]. Various techniques to improve the intraoperative control of implant positioning in total hip arthroplasty have been proposed, including systems based on plain X-rays (2D [13] or 3D [14]), computer-tomography (3D [15]) and computer navigation [16]. Potential advantages of a CT-based preoperative 3D templating include a shorter operating time and a simple intra-operative applicability as there is no need of pin placements, reference systems or other specific instruments. Based on this prospective series including 50 consecutive patients undergoing primary total hip arthroplasty, we report the accuracy of this technique by comparing pre-operative templating with postoperative radiological outcome.

Implant prediction on the femoral side was excellent, and comparable to the other series using 3D templating [15,17] and superior to prediction by 2D templating $[17,18]$. Stem size was correctly predicted in all cases. The reliability of stem size prediction is a critical aspect of the 3D templating. For example, if an undersized broach was already showing a much tighter fit than expected by the templating, a technical problem (e.g. varus position) should be assumed and meticulous evaluation of stem positioning usually reveals an intramedullary conflict, which could be resolved in all cases in this series. All modular necks have been implanted as planned. In fact, in order to avoid any contamination of the stemneck junction and hence to minimize the risk of fretting corrosion at this site, the implants (stem and neck) were assembled on the backtable in all cases before implantation. As most stems available on the market increase their offset with increasing stem size, accurate stem size prediction appears critical for an accurate reconstruction. This is confirmed by the fact that in the present series, soft-tissue tension was adequate in most patients and the planned head length had to be adapted in only $6 \%$ of the cases $(+4 \mathrm{~mm})$. Of note, due to increasing concerns in regards to corrosion issues at the body-neck junction of modular stems, we abandoned its use since completion of the study.

The planned cup size had to be increased in three patients by $2 \mathrm{~mm}$. To allow for accurate hemispheric reaming, it is our practice to start with reamer $2 \mathrm{~mm}$ smaller than the planned cup size and to follow with the reamer of the definitive cup size. Hence, due to the good predictability of the cup size, only 2 sizes of reamers were used in all but 3 cases. In addition, the reliability of implant prediction allowed the nursing staff to prepare the appropriate implants before incision. In that way, loss of time and unnecessary traffic in the operating room during surgery can be minimized.

With patients' expectations increasing over the past decades, leg length discrepancies appear to be less tolerated by patients, and respective legal aspects become more important in most countries. In the present study, planned leg-length was reproduced with an accuracy of $0.3 \mathrm{~mm} \pm 2.3$, which is comparable to other series using preoperative 3D templating [15,17]. Only one patient $(+6 \mathrm{~mm})$ has to be considered an outlier as defined by Ezzet and McCauley [19], who proposed a threshold of $5 \mathrm{~mm}$. However, no patient in our series has been complaining about a symptomatic leg lengths discrepancy. Of note, authors using 2D templating [13] based on plain X-rays and cemented stems or intra-operative x-rays [19] achieved comparable accuracies.

Preoperative femoral antetorsion and offset were highly variable in our series. Of note, despite most stems on the market increasing their offset with size, intramedullary dimensions (as reflected by stem size) did not correlate with femoral offset (data not shown). The accuracy of femoral antetorsion in our series (84\% of our patients less than $5^{\circ}$, the biggest outlier being $8^{\circ}$ ) appears slightly better (i.e. less outliers) than the one reported by Sariali et al [15] using a similar technique. We feel that intra-operative evaluation of antetorsion is difficult when using a direct anterior approach with the patient in supine position on a traction table. In view of the absence of any dislocation in this series to date (minimum 16 months of follow-up), we believe that this accuracy as sufficient. We are not aware of studies evaluating postoperative antetorsion using the same surgical technique and other techniques of pre-operative templating.

In regards to the position of the acetabular center of rotation, inaccuracy of the actual cup position was greatest in medio-lateral direction with the center of rotation placed more laterally than templated. Our standard technique, which includes the use of only two sizes of reamers, might make a sufficient medialization difficult in some cases. This is in line with Tripuraneni et al [20], who concluded from their series of 75 primary THAs that incomplete medialization is a common error in the execution of preoperative templating. In the present series, the center of rotation was positioned more anteriorly than posteriorly. This may be explained by the fact that with the direction of the reamer perpendicular to the plane of the acetabular rim towards medial/posterior, the center of rotation moves posteriorly the deeper the cup is seated.

While acetabular cup inclination was within $10^{\circ}$ of our target $\left(45^{\circ}\right)$ in all cases, cup anteversion was increased by $6.9^{\circ} \pm 11.4^{\circ}$. Comparable results were reported by others using the same technique [15]. Eggli et al [13] reported in their series using preoperative 2D templating an increase of $9^{\circ} \pm 3^{\circ}$ based on a comparison of preoperative plan and postoperative $\mathrm{x}$-ray. The accuracy of techniques applying computer navigation appears to be considerably superior in this regard [21].

The strength of this study is the homogeneity of the series in terms of technique and implants and the fact that all patients have been operated by the same surgeon. Fusing the pre and postoperative CT scans allows for a maximal accuracy. However, it remains to be determined how much the achieved accuracy translates into a relevant benefit for the patient.

The weakness of every CT-based technique for templating includes the additional costs that are imparted to the economic burden of hip arthroplasty on health care systems. In addition, the CT-protocol used in this study exposes the patients to a mean effective dose of $4.0 \mathrm{mSv}$ $( \pm 0.9 \mathrm{mSv})[22]$.

In conclusion, preoperative CT-based 3D templating allows for an accurate assessment of the individual anatomy of patients undergoing THA. Implant size prediction is reliable and the accuracy of stem positioning is excellent. However, no advantage is observed in terms of cup orientation when compared to studies involving 2D templating or navigation. Further research comparing various techniques of preoperative templating with navigation is necessary.

\section{References}

1. Chandler RW, Dorr LD, Perry J. The functional cost of dislocation following total hip arthroplasty. Clin Orthop Relat Res 1982(168):168.

2. Hedlundh $\mathrm{U}$, Ahnfelt L, Hybbinette $\mathrm{CH}$, et al. Surgical experience related to dislocations after total hip arthroplasty. J Bone Joint Surg Br 1996;78(2):206.

3. Vielpeau C, Lebel B, Ardouin L, et al. The dual mobility socket concept: experience with 668 cases. Int Orthop 2011;35(2):225.

4. Cogan A, Klouche S, Mamoudy $\mathrm{P}$, et al. Total hip arthroplasty dislocation rate following isolated cup revision using Hueter's direct anterior approach on a fracture table. Orthop Traumatol Surg Res 2011;97(5):501.

5. Langlais FL, Ropars M, Gaucher F, et al. Dual mobility cemented cups have low dislocation rates in THA revisions. Clin Orthop Relat Res 2008;466(2):389.

6. Pineau V, Lebel B, Gouzy S, et al. Dual mobility hip arthroplasty wear measurement: experimental accuracy assessment using radiostereometric analysis (RSA). Orthop Traumatol Surg Res 2010;96(6):609.

7. Hueter C. Grundriss der Chirurgie: Vogel, F.C.W., 1883

8. Philippot R, Adam P, Reckhaus M, et al. Prevention of dislocation in total hip revision surgery using a dual mobility design. Orthop Traumatol Surg Res 2009;95 (6):407.

9. Guyen O, Chen QS, Bejui-Hugues J, et al. Unconstrained tripolar hip implants: effect on hip stability. Clin Orthop Relat Res 2007;455:202.

10. Asayama I, Naito M, Fujisawa M, et al. Relationship between radiographic measurements of reconstructed hip joint position and the Trendelenburg sign. J Arthroplasty 2002;17(6):747.

11. Yoshimine F. The safe-zones for combined cup and neck anteversions that fulfill the essential range of motion and their optimum combination in total hip replacements. J Biomech 2006;39(7):1315.

12. Lewinnek GE, Lewis JL, Tarr R, et al. Dislocations after total hip-replacement arthroplasties. J Bone Joint Surg Am 1978;60(2):217. 
13. Eggli S, Pisan M, Muller ME. The value of preoperative planning for total hip arthroplasty. J Bone Joint Surg Br 1998;80(3):382.

14. Schumann S, Liu L, Tannast M, et al. An integrated system for 3D hip joint reconstruction from 2D X-rays: a preliminary validation study. Ann Biomed Eng 2013;41(10):2077.

15. Sariali E, Mouttet A, Pasquier G, et al. Accuracy of reconstruction of the hip using computerised three-dimensional pre-operative planning and a cementless modular neck. J Bone Joint Surg Br 2009;91(3):333.

16. Gurgel HM, Croci AT, Cabrita HA, et al. Acetabular component positioning in total hip arthroplasty with and without a computer-assisted system: a prospective, randomized and controlled study. J Arthroplasty 2014;29(1):167.

17. Sariali E, Mauprivez R, Khiami F, et al. Accuracy of the preoperative planning for cementless total hip arthroplasty. A randomised comparison between threedimensional computerised planning and conventional templating. Orthop Traumatol Surg Res 2012;98(2):151.
18. Kniesel B, Konstantinidis L, Hirschmuller A, et al. Digital templating in total knee and hip replacement: an analysis of planning accuracy. Int Orthop 2013. http://dx. doi.org/10.1007/s00264-013-2157-1.

19. Ezzet KA, McCauley JC. Use of intraoperative $\mathrm{x}$-rays to optimize component position and leg length during total hip arthroplasty. J Arthroplasty 2013. http://dx. doi.org/10.1016/j.arth.2013.08.003.

20. Tripuraneni KR, Archibeck MJ, Junick DW, et al. Common errors in the execution of preoperative templating for primary total hip arthroplasty. J Arthroplasty 2010;25 (8):1235.

21. Lin F, Lim D, Wixson RL, et al. Limitations of imageless computer-assisted navigation for total hip arthroplasty. J Arthroplasty 2011;26(4):596.

22. Huppertz A, Radmer S, Asbach $P$, et al. Computed tomography for preoperative planning in minimal-invasive total hip arthroplasty: radiation exposure and cost analysis. Eur J Radiol 2011;78(3):406. 